\title{
Reestruturação e expansão do ensino superior público: o programa Reuni na Universidade Federal do Ceará sob a visão dos alunos
}

Augusto Cézar de Aquino Cabral; Claudia Bubamra Abreu Romero; Emanuel Diego dos Santos Penha; Emanuel Dheison dos Santos Penha; Rafael de Almeida Alves e Tobias Coutinho Parente

\section{Introdução}

No contexto socioeconômico e político atual, os países emergentes têm, crescentemente, assumido relevância estratégica no cenário internacional, como tem sido o caso daqueles que passaram a ser conhecidos pelo acróstico BRICS, formado pelas letras iniciais de Brasil, Rússia, Índia, China e África do Sul. Estes países aspiram ascender ao nível de desenvolvimento dos países de primeiro mundo, embora ainda enfrentem muitas barreiras. No caso do Brasil, conforme afirma Reid (2008), um dos principais obstáculos ao desenvolvimento duradouro é a baixa qualidade do sistema educacional, que se caracteriza por não atender às demandas sociais de inclusão e qualificação profissional.

O setor privado tem preenchido parcialmente esta lacuna. O que tem sido feito com êxito em alguns casos, na perspectiva da educação. Porém, em geral, são as instituições de ensino superior (IES) públicas que melhor cumprem a totalidade de ações próprias de uma universidade, como constatado na Sinopse 
Estatística da Educação Superior, do Instituto Nacional de Estudos e Pesquisas Educacionais Anísio Teixeira (INEP, 2007).

A Sinopse Estatística da Educação Superior detectou que o corpo docente das IES públicas possui maior nível de qualificação, sendo composto por $42,87 \%$ de doutores, 28,91\% de mestres e 16,03\% de pós-graduados na modalidade lato sensu; já as IES privadas são compostas por 12,29\% de doutores, 39,69\% de mestres e $36,80 \%$ de pós-graduados na modalidade lato sensu. Percebe-se também o alto nível dos estudantes das IES públicas, devido aos rigorosos processos seletivos. Isso tem a ver com o fato de que, para cada vaga oferecida nas IES públicas, há uma média de 6,96 candidatos concorrendo pela vaga; em quanto que nas IES privadas esta média é de apenas 1,16. Diante desses fatos, o governo federal encontra elementos que legitimam sua decisão de fortalecer as IES públicas em todo o país. Uma das principais estratégias utilizadas foi o Programa de Reestruturação e Expansão das Universidades Federais (REUNI), objeto de estudo desta pesquisa.

$\mathrm{Na}$ busca de oportunidades de melhoria, o Reuni tem papel relevante para viabilizar o acesso aos recursos financeiros fundamentais para modernização e melhoria da educação, em especial no âmbito da graduação. Contudo, por sua complexidade, em termos de abrangência e desafios de metas a serem cumpridos, a adesão ao programa é de cunho estratégico, devendo considerar interesses e visões de todos os stakeholders, internos e externos, como argumenta Rowley (1977), ao abordar o tema da qualidade em ensino superior. Entre as questões a serem enfrentadas, destaca-se a necessidade de monitoramento das percepções do corpo discente quanto ao seu nível de conhecimento e satisfação acerca do Programa Reuni na concepção do governo federal e, em especial, nos moldes em que o programa é implantado em cada instituição. Como afirma Grey (2004), esse tipo de monitoramento ajuda na retenção e no engajamento dos estudantes, estimulando sua integração à instituição e aos seus programas.

Com a adesão ao Reuni, surgiram, em diversas instituições, algumas polêmicas e a principal delas, conforme Rodrigues (2008), foi a necessidade de uma maior discussão sobre as propostas, com intuito de identificar as prioridades de cada universidade. Nesse contexto, torna-se relevante investigar a percepção dos estudantes em relação às propostas de adesão das universidades ao Reuni e a opinião deles sobre o Programa, bem como os fatores que moldam essa opinião. Portanto, ao se fazer este estudo, busca-se identificar em que, exatamente, se fundamenta essa polêmica: se estaria ligada à real contestação das propostas de adesão das universidades por parte dos estudantes, ou seria somente um ressentimento dos estudantes por não participarem da elaboração da proposta. Ou seja, há elementos concretos que dão suporte aos questionamentos feitos ou prevalece a desinformação sobre o tema?

Para realizar esta pesquisa, escolheuse a Universidade Federal do Ceará (UFC), devido à importância dessa universidade no contexto das IES brasileiras, como ilustram algumas evidências. No rol da Webometrics Ranking of World Universities (2010), que classifica as universidades da América Latina e do Brasil de acordo com o impacto da produção científica da instituição na internet, a UFC se destaca tanto na perspectiva nacional, ocupando a $25^{\text {a }}$ posição na lista, quanto na perspectiva continental, ocupando a $59^{a}$ posição. 
Ressalta-se, ainda, o fato de a UFC ter sido umas das primeiras IES a aderir ao Programa. Ademais, a acessibilidade aos estudantes da instituição foi determinante nessa escolha, dada a vinculação dos pesquisadores a este fator.

Quanto à escolha dos respondentes, os estudantes foram escolhidos por constituírem o maior grupo que compõe a comunidade acadêmica e por serem o grupo mais diretamente afetado pelas ações do programa, dado que as propostas são voltadas para a graduação, lançando, conjuntamente, o desafio da expansão e da melhoria da qualidade. Dessa forma, a pesquisa utiliza uma amostra de 378 estudantes, determinada por meio da fórmula de Cochran (1977) para populações finitas e amostras aleatórias estratificadas, para captar a percepção dos estudantes sobre o Reuni.

Os estudantes da UFC em Fortaleza eram bastante heterogêneos e estavam divididos, à época da pesquisa, em 10 unidades acadêmicas distribuídas em quatro campi, os quais, em princípio, possuíam subculturas, visões políticas e condições sociais distintas. Estima-se que a percepção dos estudantes sobre o Reuni é influenciada pelo impacto dessas variáveis. Sendo assim, a pesquisa, realizada sob a perspectiva da administração mercadológica, parte da hipótese de que a percepção dos estudantes é moldada pelas variáveis que influenciam seu comportamento como consumidor e usuário dos serviços e produtos da universidade, e que se abrigam sob o guardachuva do conceito de educação.

Outra hipótese a ser verificada é a de que os estudantes estão, em geral, desinformados acerca das ações propostas pela UFC, o que levaria a avaliação daqueles que têm uma opinião negativa sobre o Reuni a não se diferenciar da avaliação dos detentores de uma opinião positiva. Para testar essas hipóteses e alcançar o objetivo geral da pesquisa, definiram-se os seguintes objetivos específicos: 1) verificar a diferença de percepção dos estudantes de cada unidade acadêmica da UFC; 2) constatar o nível de conhecimento dos estudantes da UFC em relação ao Reuni; e 3) levantar a opinião dos estudantes em relação à proposta da UFC para a adesão ao programa.

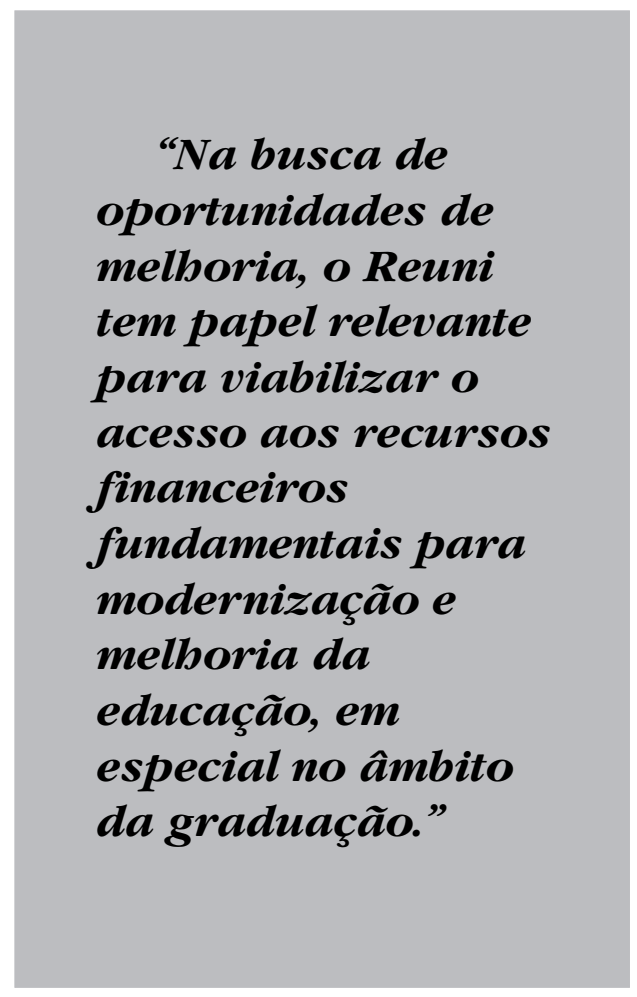

Em termos de estrutura, além desta introdução, o trabalho tem seis outros segmentos. O segundo segmento traz o referencial teórico, abordando as variáveis e fatores que afetam o comportamento do consumidor. $\mathrm{O}$ terceiro discute os aspectos metodológicos da pesquisa. O quarto apresenta o programa Reuni, conforme concebido pelo Ministério da Educação (MEC), 
e traz uma síntese de estudos sobre a adoção do Reuni em algumas instituições. O quinto traz a apresentação e análise dos dados. Por fim, o sétimo segmento apresenta as conclusões da pesquisa.

\section{Variáveis e fatores que influenciam o comportamento do consumidor}

O enfoque adotado nesta pesquisa insere-se no campo do marketing educacional (Cobra; Braga, 2004), que, tendo se iniciado no setor privado, tem ganhado relevância no setor público. Observa-se que, em geral, as organizações do segmento da educação, inclusive as universidades públicas, enfrentam hoje o desafio de aplicar estratégias e ferramentas de marketing para avaliar seus serviços e melhorar sua imagem institucional, de modo a garantir sua legitimidade social. Em grande medida, advém daí a visão do aluno-cliente, que tem suscitado diversos questionamentos, mas que, por questão de foco, foge do escopo deste trabalho.

A argumentação desenvolvida ao longo do trabalho ancora-se na crença de que instituições educacionais que integram uma abordagem mercadológica à sua gestão tendem a experimentar melhorias em sua atuação, inclusive em termos de retenção de estudantes e atendimento das necessidades de seus públicos (KotLer; Fox, 1994). Dessa forma, as IES públicas, ao adotarem conceitos mercadológicos, como a percepção das necessidades dos estudantes-clientes, podem adotar ações efetivas de melhoria voltadas a esse público, de forma a melhorar sua atuação na formação dos estudantes, bem como na redução da evasão dos estudantes dos cursos.

$\mathrm{Na}$ análise das variáveis que influenciam o comportamento dos estudantes em relação ao Reuni, foram utilizadas como referencial teórico as variáveis que influenciam o comportamento do consumidor. Assim, as mesmas variáveis que influenciam os consumidores em suas decisões, influenciam os estudantes em relação às suas atitudes e opiniões sobre o Reuni. Desta forma, é importante captar as opiniões deles sobre o programa, nos moldes propostos pelo governo federal, e sobre a proposta da UFC de adesão ao Reuni. Nessa ótica, o Reuni pode ser compreendido como um serviço que tem foco na melhoria das IES públicas para atender melhor os estudantes. Supõese, assim, que eles formam suas opiniões de modo similar ao consumidor que avalia uma marca ou produto. Para tanto, é necessário o conhecimento das variáveis e fatores que podem influenciar o comportamento do consumidor, que são os fatores culturais, sociais, pessoais e psicológicos, conforme exposto a seguir.

\section{Fatores culturais}

Kotler (2006) afirma que os fatores culturais exercem uma influência ampla e profunda no comportamento do consumidor, sendo, portanto, relevante que as organizações compreendam o papel exercido pela cultura, subcultura(s) e classe social.

- Cultura: "refere-se a um conjunto de valores, ideias, artefatos e outros símbolos significativos que ajudam os indivíduos a se comunicar, a interpretar e a avaliar como membros de uma sociedade" (BLACKWELL; Miniard; Enget, 2008, p.326). A cultura é a causa mais determinante dos desejos e do comportamento de uma pessoa, é a soma total das crenças, valores e costumes aprendidos que servem para direcionar o comportamento de consumo dos indivíduos. (SchifFMAN; KANUK 2000).

- Subcultura: "subculturas são segmentos dentro de uma cultura que 
compartilham valores e padrões de comportamento distintos, que diferem dos pertencentes à cultura geral" (CHURCHILL, JR.; Peter, 2000).

- Classe social: classes sociais são, para Castro (2004), um critério de ordenação da sociedade, o qual utiliza indicadores como poder aquisitivo, escolaridade e ocupação, cujos membros partilham valores, interesses e comportamentos.

\section{Fatores sociais}

Para Kotler (2006), o comportamento do consumidor também é influenciado por fatores sociais, por grupos a que pertence ou a que aspira pertencer, família, papéis sociais e status. Portanto, é necessário identificar a influência dessas variáveis no consumidor.

- Grupos: uma pessoa pode ser influenciada por diversos tipos de grupos. Existem os grupos de referência, que, conforme Churchill e Peter (2000), influenciam pensamentos, sentimentos e comportamentos do consumidor; grupos de afinidade, que podem ser classificados em primários - família, amigos e colegas de trabalho - ou secundários - grupos religiosos, profissionais e sindicatos e grupos de aspiração, que são grupos dos quais a pessoa aspira pertencer e que exerce uma grande influência.

- Família: a família tem grande peso na decisão final do consumidor sobre aquisição ou não de bem ou serviço. "Muitas influências se dão sobre o comportamento de um indivíduo nas famílias de orientação e de procriação" (URDAN; URDAN, 2010, p. 241). Churchill e Peter (2000, p. 162) comentam a existência dos ciclos de vida familiar, isto é, "conjunto de estágios pelos quais as famílias passam e que influenciam suas necessidades e a capacidade de satisfazê-las".
- Papéis sociais e status: as pessoas participam da família e de diversos grupos e sua posição pode ser definida por meio de papéis e status em cada um deles. O papel consiste nas atividades esperadas de uma pessoa em relação aos outros à sua volta; o status reflete a opinião geral da sociedade sobre o papel desempenhado pela pessoa. "Os elementos que conferem status dependem dos critérios adotados pelo grupo" (URDANURDAN, 2010, p. 240).

\section{Fatores pessoais}

Kotler (2006) defende que as decisões do consumidor também são influenciadas por características pessoais, como idade, ocupação, situação econômica, estilo de vida, personalidade e autoconceito, compreendidos conforme sintetizado a seguir:

- Idade: Segundo Dubois (1993), a idade é o fenômeno demográfico que mais influencia o comportamento do consumidor. Ao longo da vida, as pessoas mudam hábitos de vida e, consequentemente, de compra. A idade é uma variável que influencia até na resposta a indicações de amigos em relação a produtos e serviços (Schmitt; Skiera; Van Den Bulte, 2011).

- Ocupação e situação econômica: A ocupação também influencia o padrão de consumo de uma pessoa, e tem relação direta com sua situação econômica. "Os profissionais de marketing tentam identificar os grupos de ocupação que possuem interesses comuns em seus produtos e serviços" (KotLer, 2006, p. 180).

- Estilo de vida: Segundo Blackwell, Miniard e Engel (2008), estilo de vida é um constructo sumário definido como padrões em que as pessoas vivem e gastam tempo e dinheiro, refletindo as atividades, os interesses e as opiniões das pessoas, assim como as variáveis demográficas que as caracterizam. Os autores afirmam que 
as pessoas utilizam constructos como estilo de vida para analisar e interpretar os eventos que acontecem à sua volta.

- Personalidade e autoconceito: personalidade é o conjunto de traços psicológicos únicos que levam a reações relativamente coerentes e duradouras com o ambiente do indivíduo. Richers (1984) afirma que a personalidade é composta por uma multiplicidade de componentes que incluem valores, atitudes, crenças, motivos, intenções, interesses e normas culturais. $\mathrm{O}$ autoconceito é a premissa básica de que as posses refletem a personalidade, ou seja, as pessoas são o que possuem.

\section{Fatores psicológicos}

Segundo Kotler (2006), as escolhas de compra do consumidor também são afetadas por fatores psicológicos como motivação, percepção, aprendizado, crenças e atitudes.

- Motivação: A motivação é uma necessidade de ordem física, social ou psicológica. A clássica teoria das necessidades de Maslow (1954) classifica as necessidades em uma hierarquia ascendente, desde as de ordem fisiológica, seguidas pelas de segurança, necessidades sociais, e de estima e autorrealização.

- Percepção: De acordo com Urdan e Urdan (2010, p. 276), "percepção é o processo de seleção, organização e interpretação de informações recebidas por uma pessoa para gerar significados, o que depois acabará afetando seu comportamento". Las Casas (2009, p. 161) afirma que "a percepção muda com o nível de conhecimento e a familiaridade que se tem com os assuntos".

- Aprendizado: "A aprendizagem consiste em mudanças de comportamento de uma pessoa decorrentes da experiência" (Kotler, 2006, p. 184). Richers (1984, p. 50) salienta que "o homem é capaz de aprender e alterar os seus comportamentos através da ampla utilização de sua experiência passada". O autor ainda apresenta duas explicações psicológicas para a natureza do aprendizado: a cognitiva (por meio da qual o indivíduo se conscientiza de um estímulo) e a afetiva (que ocorre quando alguém começa a apreciar o estímulo após tornar-se consciente dele).

- Conhecimento: Segundo Urdan e Urdan (2010), conhecimento são as informações acumuladas e registradas na memória e que podem ser lembradas e utilizadas nas tomadas de decisões.

- Crenças e atitudes: Solomon (2002) conceitua atitude como uma avaliação duradoura e geral das pessoas em relação a pessoas, objetos, propagandas e questões. Mowen e Minor (2003) corroboram, afirmando que enquanto a crença é o conhecimento cognitivo acerca de um objeto, a atitude é o sentimento que as pessoas têm em relação aos objetos.

Diante das inúmeras variáveis que influenciam o comportamento dos indivíduos e grupos e da necessidade de se identificar quais são as variáveis que exercem maior influência sobre as atitudes e comportamentos de estudantes universitários, ganha relevância pesquisar o que pensam os estudantes da UFC em relação ao Reuni e à decisão da UFC de aderir ao programa, à luz das variáveis que interferem em suas atitudes e comportamentos.

\section{Metodologia}

A pesquisa é de natureza quantitativa, tendo sido realizada mediante survey. Logo, a obtenção de informações baseiase no interrogatório dos participantes, aos quais se fazem várias perguntas sobre seus comportamentos e atitudes, em 
alinhamento ao que argumenta Malhotra (2001) acerca desse tipo de estudo. Ainda conforme a taxionomia do autor, a pesquisa pode ser caracterizada quanto aos fins como descritiva e conclusiva, pois busca estudar uma determinada população ou fenômeno, no caso os estudantes da UFC, utilizando-se uma análise quantitativa, a partir de uma amostra grande e representativa.

Quanto aos meios, tomando-se por base Mattar (2001), categoriza-se esta pesquisa como sendo um levantamento de campo, por procurar dados representativos da população de interesse, tanto em relação ao número de casos incluídos na amostra quanto à forma de sua inclusão.

Quanto à coleta de dados primários, foram utilizados questionários autopreenchidos, estruturados em três partes: a primeira corresponde à caracterização do respondente; a segunda, às ações que a UFC se propôs a realizar dentro das diretrizes que o MEC repassou para as universidades; e a terceira, às percepções dos estudantes sobre o Reuni.

Como o objetivo geral desta pesquisa é captar a percepção dos estudantes em relação à proposta de adesão da UFC ao Reuni, fez-se necessário alocar, na segunda parte do questionário, as ações que a UFC se propôs a realizar para se alinhar às diretrizes do programa. Para evitar possíveis pré-julgamentos de teor negativo por parte dos estudantes em relação às propostas da UFC citadas no questionário, foi omitido o fato de que, nesta parte, os estudantes estavam avaliando as propostas da UFC de adesão ao Reuni; pois, segundo Ahluwalia, Burnkrant e Unnava (2000), as pessoas com fortes atitudes são tidas como mais resistentes às informações que são contrárias às suas impressões, principalmente informações negativas sobre organizações. A omissão se justifica ao se considerar uma das hipóteses da pesquisa: de que a avaliação dos estudantes detentores de uma opinião negativa sobre o Reuni não se diferencia da daqueles que avaliam positivamente as propostas da UFC de adesão ao programa. A pesquisa poderia ficar prejudicada, caso os estudantes soubessem que estavam avaliando as propostas da UFC de adesão ao Reuni.

“O programa tem como meta global a elevação gradual da taxa de conchsão média dos cursos de graduação presenciais para 90\%, e da relação de estudantes de graduação em cursos presenciais por professor para 18, ao final de cinco anos (BRAsIL, 2008)."

$\mathrm{Na}$ análise deste segmento da pesquisa, foram quantificadas as respostas de cada estudante em uma pesquisa de opinião em escala Likert, variando de irrelevante a extremamente relevante, com os seguintes pesos: 0 para irrelevante, 25 para pouco relevante, 50 para indiferente, 75 para relevante e 100 para extremamente relevante. Ao final, calculou-se o escore 
geral das opiniões dos estudantes em relação às ações propostas pela UFC, resultando em escore entre 0 e 100.

$\mathrm{Na}$ terceira parte, buscou-se verificar as percepções dos estudantes sobre o Reuni. Para tanto, utilizou-se questões abertas e fechadas, tendo de ser feita uma análise qualitativa baseada na categorização da análise de conteúdo (BARDIN, 1977). Nesse segmento, foi preciso saber o grau de conhecimento dos estudantes sobre o Reuni, os quais foram classificados em três grupos: os que nunca ouviram falar do programa, ou seja, não tinham nenhum conhecimento sobre o assunto; os que ouviram falar do Reuni, porém não o conheciam a ponto de formar uma opinião a respeito; e os que afirmam conhecer o programa, tendo, portanto, uma opinião formada.

A população são os estudantes de graduação da UFC de Fortaleza. Desta, retirouse uma amostra, cujo tamanho foi determinado, utilizando-se a fórmula de Cochran (1977), apresentada a seguir, para populações finitas e amostras aleatórias estratificadas. A estimativa de erro foi de $5 \%$ e o nível de confiança, de 95\%. Utilizou-se uma estimativa da proporção favorável de 50\% para todos os extratos, para garantir amostra representativa.

$$
N=\frac{z^{2} \cdot p \cdot q \cdot N}{\left[d^{2}(N-1)+z^{2} \cdot p \cdot q\right]}
$$

Fonte: Cochran (1977).

\section{Figura 1: Fórmula de Cochran.}

Onde: $N=$ população; $z=$ abscissa da curva normal; $p=$ estimativa $\mathrm{da}$ proporção favorável; $q=1$-p; $d=$ erro amostral.
A partir dessa fórmula, chegou-se ao número total de 378 amostras de estudantes, conforme evidenciado na Tabela 1. Logo, a amostra foi definida, segundo Mattar (2001), por conveniência, porque cada elemento pesquisado foi selecionado por estar disponível no local e no momento em que a pesquisa estava sendo realizada, e estratificada proporcionalmente, pois dividiu-se a população em estratos, que são as unidades acadêmicas da UFC - Fortaleza, sendo considerada a proporção estrato-população. A categorização da pesquisa por estratos justifica-se pela hipótese de que os estudantes de uma mesma unidade acadêmica têm uma percepção uniforme e variada se comparada com a de estudantes das demais unidades. Tal percepção seria derivada dos aspectos culturais e sociais de cada unidade.

Para o processamento de dados, foi feita uma codificação das questões abertas da terceira parte do questionário, parte mais qualitativa, para uma melhor análise posterior. Para analisar estatisticamente os dados, utilizou-se o software SPSS versão 15.0 para Windows (Statistical Package for Social Sciences), e para a tabulação foi necessário o Sphinxs. O método da análise foi o inferencial, que, conforme Mattar (2001), compreende um conjunto de testes que servem para julgar a validade de hipóteses estatísticas sobre a população em questão.

\section{O Programa de Apoio a Planos de Reestruturação e Expansão das Universidades Federais (Reuni)}

Instituído pelo presidente da República do Brasil, por meio do Decreto n 6.096 no dia 24 de abril de 2007, o Reuni foi criado para reestruturar e expandir as 
Tabela 1: Composição da amostra

\begin{tabular}{l|c|c}
\hline Unidade Acadêmica & População & Amostra \\
\hline Centro de Ciências & 3010 & 58 \\
\hline Centro de Ciências Agrárias & 2869 & 55 \\
\hline Centro de Humanidades & 3283 & 63 \\
\hline Centro de Tecnologia & 2626 & 51 \\
\hline Faculdade de Direito & 912 & 18 \\
\hline Faculdade de Economia, Administração, Atuária e Contabilidade & 3428 & 66 \\
\hline Faculdade de Educação & 1186 & 23 \\
\hline Faculdade de Farmácia, Odontologia e Enfermagem & 1305 & 25 \\
\hline Faculdade de Medicina & 930 & 18 \\
\hline Instituto de Ciências do Mar & 40 & 1 \\
\hline Total & 19.589 & 378 \\
\hline
\end{tabular}

Fonte: Dados da pesquisa de campo (2008).

universidades públicas federais. Suas ações fazem parte do Plano de Desenvolvimento da Educação. O programa tem como meta global a elevação gradual da taxa de conclusão média dos cursos de graduação presenciais para 90\%, e da relação de estudantes de graduação em cursos presenciais por professor para 18, ao final de cinco anos (BrasiL, 2008).

O governo federal, ao criar o Reuni, considerou diversos aspectos da educação superior brasileira, valorizando tanto os aspectos quantitativos quanto os qualitativos. Com relação aos aspectos quantitativos, o MEC considerou a Sinopse Estatística da Educação Superior de 2005, feita pelo Inep. Entre os dados mais relevantes, consta que existiam 1.192.189 matrículas de graduação em IES públicas e 3.260.967 em IES privadas. Apesar de 73\% dos estudantes de graduação serem de escolas privadas, mais de $97 \%$ da produção científica nacional é de universidades públicas e tal produção representa 1,92\% da produção mundial, sendo a $15^{a}$ maior. Esses dados evidenciam a necessidade de se criar condições para que mais estudantes possam entrar nas universidades públicas, pois o ensino superior privado mostra grandes sinais de limitação como promovedor de conhecimento.

Dentre as variáveis qualitativas consideradas no Reuni, ressalta-se o fato de que o governo federal não instituiu um modelo único para melhorar os cursos de graduação das universidades e que elas não são obrigadas a aderir ao programa. Dessa forma, respeita-se a autonomia, assim como as características de cada uma, tendo em vista suas histórias e contextos particulares.

Para que as instituições consigam alcançar a meta global traçada pelo Governo, foram criadas diretrizes e pontos específicos para cada diretriz, como sumarizado no Quadro 1. 


\section{Quadro 1: Diretrizes e pontos específicos do Reuni}

\begin{tabular}{|c|c|}
\hline Diretrizes & Pontos específicos \\
\hline $\begin{array}{l}\text { Ampliação da oferta de vagas na } \\
\text { educação superior pública }\end{array}$ & $\begin{array}{l}\text { - Aumento de vagas de ingresso, especialmente no } \\
\text { período noturno. } \\
\text { - Redução das taxas de evasão. } \\
\text { - Ocupação de vagas ociosas. }\end{array}$ \\
\hline $\begin{array}{l}\text { Reestruturação dos currículos } \\
\text { acadêmicos }\end{array}$ & $\begin{array}{l}\text { - Revisão da estrutura acadêmica, visando a cons- } \\
\text { tante elevação da qualidade. } \\
\text { - Reorganização dos cursos de graduação. } \\
\text { - Diversificação das modalidades de graduação, } \\
\text { preferencialmente com superação da profissiona- } \\
\text { lização precoce e especializada. } \\
\text { - Implantação de regimes curriculares e sistemas de } \\
\text { títulos que possibilite a construção de itinerários } \\
\text { formativos. } \\
\text { - Previsão de modelos de transição, quando for o } \\
\text { caso. }\end{array}$ \\
\hline $\begin{array}{l}\text { Renovação pedagógica da } \\
\text { educação superior }\end{array}$ & $\begin{array}{l}\text { - Articulação da educação superior com a educação } \\
\text { básica, profissional e tecnológica. } \\
\text { - Atualização de metodologias (e tecnologias) de } \\
\text { ensino-aprendizagem. } \\
\text { - Previsão de programas de capacitação pedagógica, } \\
\text { especialmente quando for o caso de } \\
\text { implementação de um novo modelo. }\end{array}$ \\
\hline Mobilidade intra e interinstitucional & $\begin{array}{l}\text { - Promoção da ampla mobilidade estudantil } \\
\text { mediante o aproveitamento de créditos e a circu- } \\
\text { lação de estudantes entre cursos e programas, e } \\
\text { entre instituições de educação. }\end{array}$ \\
\hline Compromisso social da instituição & $\begin{array}{l}\text { - Política de inclusão. } \\
\text { - Programas de assistência estudantil. } \\
\text { - Políticas de extensão universitária. }\end{array}$ \\
\hline $\begin{array}{l}\text { Suporte da pós-graduação ao desen- } \\
\text { volvimento e aperfeiçoamento quali- } \\
\text { tativo dos cursos de graduação. }\end{array}$ & $\begin{array}{l}\text { - Articulação da graduação com a pós-graduação: } \\
\text { expansão quali-quantitativa da pós-graduação } \\
\text { orientada para a renovação pedagógica da edu- } \\
\text { cação superior. }\end{array}$ \\
\hline
\end{tabular}

Fonte: Adaptado do MEC (2007, p. 11-12).

\section{Alguns estudos acadêmicos sobre experiências de adoção ao Reuni \\ No período de 2008 a 2010, Mazon et al. (2009) verificaram os custos por aluno das universidades federais brasi- leiras, comparativamente ao custo por}

aluno matriculado nas ações do Reuni. Obteve-se o resultado de que o custo por aluno de $\mathrm{R} \$ 5.981$ das universidades federais é 4,25 vezes maior do que o de $\mathrm{R} \$ 1.400$, que representa o custo por aluno do Reuni. Mediante pesquisa documental, 
concluem que as universidades públicas brasileiras carecem de uma política de financiamento que atenda às demandas exigidas pelo ensino, pesquisa e extensão e necessitam de recursos para expansão de suas atividades em níveis regionais e nacionais, e que, com o Programa de Apoio a Planos de Reestruturação e Expansão das Universidades Federais Brasileiras está se interiorizando o acesso ao ensino superior gratuito, com níveis de custos muito inferiores aos praticados atualmente pelas universidades federais brasileiras.

Cobrindo o período de 2007 a 2009, Lugão et al. (2010), mediante pesquisa documental e bibliográfica, analisaram os aspectos relevantes e pertinentes ao Reuni, e constataram que os documentos oficiais tratam da contextualização das reformas da educação superior, enquanto as produções científicas evidenciam certa desconfiança por parte dos pesquisadores em relação ao Reuni, em virtude da dificuldade relacionada ao financiamento da estrutura operacional e administrativa nas universidades, em detrimento da manutenção da qualidade de ensino, pesquisa e extensão. Ressaltam, contudo, a insuficiência de pesquisas sobre o tema, devido à sua recente implantação.

Araújo e Pinheiro (2010) examinaram os dispositivos do Reuni, discutindo sua eficiência e investigando se o plano se adequava ao ideário de reforma dos sistemas educacionais em outras partes do mundo. Realizaram uma avaliação para estabelecer as afinidades existentes entre as propostas de reforma do Estado e do Sistema Educacional. Concluíram que o Reuni procurava dar resposta à crise do sistema de ensino superior, valorizando a introdução de novos arranjos organizacionais e mecanismos de gestão, com vistas a uma maior eficiência dos gastos públicos e alcance dos melhores resultados a curto prazo. Sendo um programa em fase de implementação, o Reuni apresentou uma série de questionamentos sobre sua capacidade de promover mudanças para o sistema de ensino superior, alterando a cultura burocrática para uma cultura de resultados.

Ravazoli (2011) delineou o cenário nacional da expansão do ensino superior. Tomando como objeto de estudo a

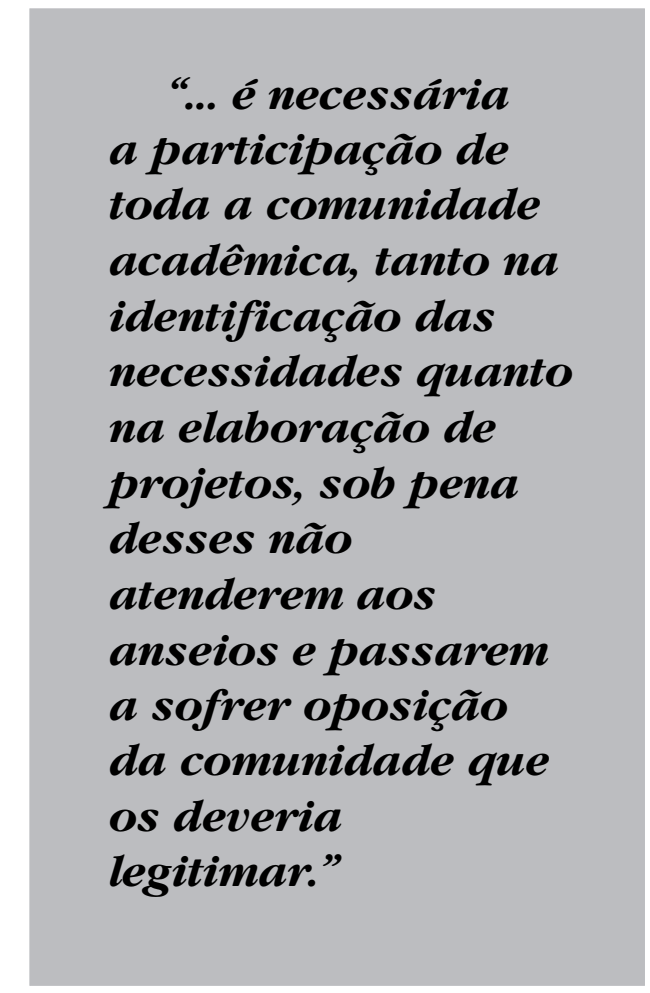

Universidade Federal do Paraná (UFPR) e a Universidade Tecnológica Federal do Paraná (UTFPR), analisou os reflexos promovidos em dois anos de implantação do Reuni nessas duas instituições. Com base no Censo da Educação Superior do Inep, constatou que houve expansão desse nível de ensino em âmbito nacional. Os esforços para aumentar as matrículas, vagas e cursos noturnos têm surtido 
efeitos positivos, combatendo o caráter elitista da educação superior. Com relação aos impactos iniciais do Reuni, a pesquisa evidenciou avanços na expansão das duas universidades. Foi registrado aumento de abertura de vagas, de cursos de graduação presenciais, de matrículas, de ações em prol da ocupação de vagas ociosas, bem como da permanência dos estudantes. A maioria das ações ultrapassou o previsto nos planos do Reuni. Sobre a evasão e a desistência, ambas as universidades empreenderam esforços para verificar suas causas e implementaram ações de acompanhamento para alunos em situação de risco. A UFPR e a UTFPR ainda estão distantes da meta de 18 estudantes por docente. No entanto, há de se considerar que grande parte dos professores das universidades federais não se dedica apenas a atividades de ensino, mas está envolvida com pesquisa e extensão, diferentemente das instituições privadas. Concluiu-se que o Reuni tem promovido a expansão do ensino superior nas duas universidades e levado a comunidade a refletir sobre suas práticas e suas formas de inclusão e exclusão.

Mediante pesquisa bibliográfica e documental, Brito e Heiden (2011) analisaram as ações institucionais relacionadas à adesão da Universidade Federal de Pelotas ao Reuni. Concluíram que o programa abriu afluentes na universidade, dando visibilidade a territórios até então incontestáveis no âmbito da UFPEL: fez aparecer o projeto pedagógico como mecanismo de gestão, trouxe o currículo acadêmico para uma criação cotidiana e coletiva, criou linhas de resistência para conceitos antes não experimentados, reivindicou o direito a espaços qualificados e qualificadores das propostas acadêmicas, além de colocar em pauta o trabalho docente e suas conexões com a sociedade.

Costa et al. (2011), por meio de pesquisa documental, analisaram o fenômeno de expansão da educação superior brasileira, impulsionada pela iniciativa e financiamento público. Verificaram que o Reuni se destacava entre os programas públicos de expansão, focando a expansão das vagas no ensino superior federal presencial e o aumento do número de cursos de graduação para 3.601 em 2012, assim como o número de vagas para 227.260 no mesmo período. Como conclusão, os autores afirmaram que o Reuni e o ProUni, articulados com o Fies, UAB e Ifes, constituem os pilares de sustentação da atual transformação do ensino superior, que abrange o ensino superior público, privado, o ensino a distância, e o ensino tecnológico. A democratização do ensino superior é essencial para o Brasil, como país que deseja alcançar a meta de se tornar a $5^{a}$ potência mundial na próxima década, e contribui para maior desenvolvimento econômico do país.

\section{Apresentação e análise dos dados da pesquisa de campo}

A partir da análise dos questionários, constatou-se que cerca de metade dos estudantes pesquisados ouviu falar do Reuni (49,5\%), e que $56,7 \%$ desses ouviram falar do programa em conversa entre amigos. Apenas 35,7\% dos estudantes pesquisados conhecem o Reuni. Desses, 40\% acham que ninguém será beneficiado com o programa, e apenas $20,7 \%$ dos que o conhecem, aprovam. Do total de estudantes entrevistados que conhecem o Reuni, 74,8\% acham que ele não vai alcançar seu objetivo, que é "democratizar o acesso ao ensino superior pelo aumento do número das vagas". 
Considerando esses resultados, percebeu-se que os estudantes da UFC, como era esperado, estão, em sua maioria, desinformados sobre o Reuni, a ponto de metade deles nunca ter ouvido falar do programa e apenas $35,7 \%$ afirmar conhecê-lo.

Outra questão abordada, foi a forma como os estudantes conheceram o programa. Os resultados estão sumarizados na Tabela 2.
A tabela 2 evidencia que a maioria dos estudantes conheceu o Reuni mediante discussão entre amigos, o que não é o meio mais adequado por ser carregado de subjetividade. Apenas 22\% afirmaram ter participado de reuniões na universidade sobre o programa.

Com relação às diretrizes do Reuni, os estudantes as avaliaram em uma escala crescente de importância de 1 a 6 , conforme demonstrado na Tabela 3.

Tabela 2: Como os estudantes conheceram o Reuni

\begin{tabular}{l|l}
\hline Como os estudantes conheceram o Reuni & $\%$ \\
\hline Discussão entre amigos & $57 \%$ \\
\hline Panfletos & $37 \%$ \\
\hline Reuniões - UFC & $22 \%$ \\
\hline Jornais & $17 \%$ \\
\hline Internet & $16 \%$ \\
\hline Televisão & $13 \%$ \\
\hline Outros & $11 \%$ \\
\hline
\end{tabular}

Fonte: Pesquisa de campo (2008)

Tabela 3: Avaliação das diretrizes do Reuni

\begin{tabular}{c|l|c}
\hline Importância & Diretrizes & Média \\
\hline $1^{a}$ & Reformulação da metodologia de ensino & 4,14 \\
\hline $2^{a}$ & $\begin{array}{l}\text { Ampliar os programas de assistência social } \\
\text { aos estudantes }\end{array}$ & 3,69 \\
\hline $3^{a}$ & Reestruturar o currículo acadêmico dos cursos & 3,68 \\
\hline $4^{a}$ & Interação entre pós-graduação e graduação & 3,61 \\
\hline $5^{a}$ & Ampliar o processo de mobilidade acadêmica & 3,13 \\
\hline $6^{a}$ & Ampliar a oferta de vagas & 2,74 \\
\hline
\end{tabular}

Fonte: Pesquisa de campo (2008) 
Com relação aos pontos positivos e negativos do Reuni, os estudantes que afirmaram conhecer o programa, enumeraram os seguintes aspectos.

\section{Tabela 4: Avaliação dos pontos positivos do Reuni}

\begin{tabular}{lc}
\hline Pontos Positivos & $\mathbf{\%}$ \\
\hline Aumento do número de vagas & 32,17 \\
\hline Aumento de intercâmbio & 26,09 \\
\hline Aumento de verbas & 17,39 \\
\hline Melhorias estruturais & 10,43 \\
\hline Outros & 13,91 \\
\hline
\end{tabular}

Fonte: Pesquisa de campo (2008).

Contrastando esses dados, verificou-se que, dos estudantes que afirmaram conhecer o Reuni, 40\% temem que com a implementação do programa o ensino perderia qualidade, item mais valorizado na avaliação das diretrizes do Reuni, em que o $1^{\circ}$ item e o $3^{\circ}$ item se referem à qualidade de ensino. Já 32,17\% deles afirmaram que o aumento do número de vagas é o principal ponto positivo do programa. A partir desses dados, verificou-se que a questão do aumento do número de vagas é um paradoxo para os estudantes, pois, apesar de ter sido considerado como principal ponto positivo para os estudantes que afirmam conhecer o Reuni, essa diretriz foi a que recebeu a pior avaliação dos estudantes. Os respondentes que ressaltam como principal ponto positivo o aumento do número de vagas avaliaram a diretriz de ampliação da oferta de vagas como sendo a segunda pior, com média de 2,95, o que fica bem próximo da média de todos os estudantes, como se pode verificar na Tabela 3 . Isso demonstra o desconhecimento dos estudantes que afirmaram conhecer o Reuni, pois não citaram as outras quatro diretrizes que foram mais bem avaliadas na segunda parte do questionário. Também vale ressaltar que o segundo ponto negativo mais citado foi a falta de

\section{Tabela 5: Avaliação dos pontos negativos do Reuni}

\begin{tabular}{lc}
\hline Pontos Negativos & $\mathbf{0}$ \\
\hline Pode reduzir a qualidade & 40 \\
\hline Falta divulgação e discussão & 14,29 \\
\hline Aumento do número de vagas & 10,48 \\
\hline Influências políticas & 10,48 \\
\hline Nenhum & 7,62 \\
\hline
\end{tabular}

Fonte: Pesquisa de campo (2008).

divulgação e discussão, o que pode ser uma das causas do desconhecimento dos estudantes.

A partir das análises feitas, percebeuse que, entre o conjunto de propostas da UFC para atender às diretrizes do Reuni, os estudantes a avaliaram conforme sintetizado na Tabela 6.

Procurou-se, em seguida, identificar a opinião dos estudantes sobre cada proposta da UFC para atender às diretrizes do Reuni, com o intuito de se identificar quais ações são tidas como relevantes. O resultado está nas Tabelas 7 e 8 .

A partir desses dados, foi possível comparar os diferentes escores das unidades acadêmicas da UFC por meio do teste Kruskal-Wallis, disponibilizado no software SPSS, que identificou diferenças estatisticamente válidas nas avaliações dos estudantes de cada centro (para um $p=0,01$ ). Após essa conclusão, foi utilizado o teste de MannWhitney, que comparou o grau de avaliação dos diferentes centros aos pares. Assim, chegou-se à conclusão de que existem diferenças estatisticamente válidas entre as 
Tabela 6: Avaliação do conjunto de propostas da UFC para cada diretriz do Reuni

\begin{tabular}{l|c}
\hline Conjunto de propostas da UFC para as diretrizes do Reuni & Média \\
\hline Programas de assistência social & 79,66 \\
\hline Mobilidade dos estudantes entre as universidades & 77,26 \\
\hline Participação da pós-graduação na graduação & 77,22 \\
\hline Ampliação da oferta de vagas & 72,89 \\
\hline Reformulação da metodologia de ensino & 70,61 \\
\hline Reestruturação dos currículos acadêmicos & 69,96 \\
\hline
\end{tabular}

Fonte: Pesquisa de campo (2008).

Tabela 7: Propostas da UFC mais bem avaliadas

\begin{tabular}{l|c}
\hline Propostas & Média \\
\hline Ampliar o acesso e reforma dos laboratórios e bibliotecas & 89,91 \\
\hline Potencializar a interação entre o ensino e a pesquisa & 88,27 \\
\hline Ampliar bolsa de assistência & 84,09 \\
\hline Ampliar bolsas de monitoria & 82,78 \\
\hline Ampliar as interações entre graduação e pós-graduação & 80,59 \\
\hline
\end{tabular}

Fonte: Pesquisa de Campo (2008).

Tabela 8: Propostas da UFC mal avaliadas

\begin{tabular}{l|l}
\hline Propostas & Média \\
\hline $\begin{array}{l}\text { Inclusão da modalidade tecnólogo como etapa de alguns cursos de } \\
\text { modalidade profissional }\end{array}$ & 54,04 \\
\hline $\begin{array}{l}\text { Inserir a modalidade licenciatura em cursos bacharelados e bacharelados } \\
\text { em cursos de licenciatura }\end{array}$ & 56,68 \\
\hline Vagas para os servidores na graduação & 57,31 \\
\hline Expansão nas áreas artísticas, culturais e esportivas & 67,52 \\
\hline Reestruturar o vestibular & 68,87 \\
\hline
\end{tabular}

Fonte: Pesquisa de Campo (2008). 
unidades; entre essas, o Centro de Ciências Agrárias e as respectivas unidades: Centro de Ciências $(p=0,001)$; Centro de Humanidades $(p=0,014)$; Centro de Tecnologia $(p=0,01)$; Faculdade de Economia, Administração, Atuária e Contabilidade ( $p=0,004)$; Faculdade de Medicina $(p=0,007)$.

A diferença verificada é que os estudantes do Centro de Ciências Agrárias têm uma melhor avaliação da proposta de adesão da UFC ao Reuni do que os dos demais centros. A Faculdade de Farmácia, Odontologia e Enfermagem também se demonstrou diferente das unidades: Faculdade de Medicina $(p=0,05)$ e Centro de Ciências $(p=0,014)$; os estudantes da Faculdade de Farmácia, Odontologia e Enfermagem avaliaram melhor a proposta do que os das demais unidades.

O teste de Mann-Whitney também foi utilizado para comparar o escore de avaliação das propostas da UFC de adesão ao Reuni: por parte dos que estavam (ou não) informados sobre o programa. O resultado demonstrou que não existe diferença nessa avaliação $(\mathrm{p}=0,470)$, o que confirma a segunda hipótese da pesquisa. Esse mesmo teste ajudou a perceber que não existe diferença de escore de avaliação da proposta da UFC de quem aprova o Reuni, se comparado com o de quem não aprova o programa $(p=0,937)$.

\section{Variáveis e fatores que influenciam a opinião dos estudantes da UFC sobre o Reuni}

Como ressaltado no referencial teórico, diversas variáveis influenciam na formação de opinião dos estudantes sobre a proposta de adesão da UFC ao Reuni. Com a pesquisa, verificou-se que as variáveis que mais influenciaram na formação de opinião dos estudantes foram: subculturas - que é um fator cultural; grupos - que é um fator social; idade e situação econômica - que são fatores pessoais; e atitudes - que são fatores psicológicos.

O impacto da variável "subcultura" pode ser verificado por meio da diferença da avaliação da proposta de adesão da UFC ao Reuni, em que se verificou que a unidade Centro de Ciências Agrárias diferenciouse de outras cinco unidades; e a Faculdade de Farmácia, Odontologia e Enfermagem, de outras duas, como demonstrado anteriormente. Pode-se atribuir essas diferenças às particularidades culturais de cada unidade acadêmica. Também se verificou a atitude dos estudantes de cada unidade. Constatou-se que em oito das dez unidades a maioria dos estudantes possui uma atitude negativa em relação ao Reuni; ou seja, os estudantes dessas unidades que afirmaram conhecer o Reuni não aprovavam, por ocasião da pesquisa, o programa da maneira como implementado.

Percebeu-se a influência da variável "social" dos grupos ao se observar como os estudantes tomaram conhecimento do Reuni. Segundo os dados, 57\% dos estudantes conheceram o programa por meio de discussão com os amigos. O que caracteriza uma forte influência do grupo social, no caso os amigos, na formação de opinião dos estudantes.

Dentre os fatores analisados, percebeuse uma influência maior dos fatores pessoais. Identificou-se a influência da variável "idade" por meio do índice de correlações de Spearman, que resultou em um índice de 0,174 de relação entre o escore de avaliação do Reuni e a idade; ou seja, quanto maior a idade melhor a avaliação da proposta da UFC ao Reuni. Com relação ao impacto da variável "situação econômica", verificou-se a sua influência por meio da correlação 
encontrada de $-0,170$, para avaliação do Reuni e renda familiar; ou seja, quanto menor a renda melhor a avaliação da proposta da UFC (ambas para um $p=0,01$ ). Porém, segundo o teste Qui-quadrado, essa diferença de avaliação não se refere ao menor nível de informação por parte das pessoas que possuem menor renda, pois percebeu-se que não existe diferença estatisticamente significante entre as proporções de quem ouviu falar ou não do Reuni em relação à renda (para um $p=0,81)$. Ou seja, apesar de quem tem mais renda ter maior acesso à informação, constatou-se que o nível de conhecimento sobre o Reuni é o mesmo para qualquer situação econômica do aluno.

Por fim, percebeu-se, entre os estudantes que afirmaram conhecer o programa, forte atitude negativa em relação ao Reuni, pois $72,6 \%$ o desaprovam e $74,8 \%$ acreditam que o programa não atingirá seu objetivo, caracterizando a influência desse fator psicológico na formação da opinião dos estudantes sobre o próprio programa.

\section{Conclusões}

No contexto de expansão do ensino superior para atender às necessidades crescentes da população, a realização desta pesquisa mostrou-se oportuna para identificar se as reais necessidades dos estudantes de uma IES - a Universidade Federal do Ceará (UFC) -, são atendidas pelo programa de Reestruturação e Expansão das Universidades Federais (Reuni) e pela proposta de adesão dessa instituição. A pesquisa identificou alguns fatores que influenciam a percepção das necessidades dos estudantes, destacando-se as seguintes variáveis: subculturas de cada centro, grupos, idade, situação econômica e atitudes, como se pôde observar na análise dos resultados.

Nos resultados obtidos, percebeu-se que os estudantes da UFC avaliam de forma positiva a proposta da UFC para adesão ao Reuni, ainda que reprovando a implementação do programa. Os estudantes temem a redução da qualidade do ensino, pois acreditam que um possível aumento de vagas não seria acompanhado de melhor aproveitamento ou expansão da estrutura existente da UFC. Muitos estudantes acreditam que a atual estrutura não suporta o número de alunos da universidade, sem considerar, contudo, que o programa contempla a reestruturação física.

Quanto às hipóteses da pesquisa, percebeu-se que não existe diferença de percepção dos estudantes da maioria das unidades acadêmicas em relação à proposta da UFC e ao Reuni; ou seja, as subculturas de cada unidade não tiveram forte influência na avaliação dos estudantes da proposta da UFC. Foi verificada uma influência mais forte de variáveis individuais, como idade e situação econômica. Entretanto, faz-se necessário ressaltar que duas unidades em especial - Centro de Ciências Agrárias e Faculdade de Farmácia, Odontologia e Enfermagem - apresentaram percepção diferente das demais unidades em relação à proposta da UFC.

Também foi observado que as atitudes dos estudantes em relação ao programa não influenciaram sua avaliação das propostas da UFC; ou seja, tanto os estudantes que cultivavam uma atitude contrária ao programa quanto aqueles que tinham uma atitude favorável têm uma avaliação similar das propostas da UFC.

Em relação à segunda hipótese, verificou-se que os estudantes que rejeitam o Reuni apresentam nível de aprovação da 
proposta da UFC similar aos que aprovam o Reuni, comprovando que os estudantes que reprovam o programa não possuem conhecimento profundo sobre o Reuni e a proposta da UFC. Isso se deve muito a uma promoção insuficiente por parte da universidade junto à comunidade acadêmica e a uma promoção inapropriada, realizada por grupos que detinham pouco conhecimento do programa ou que o rejeitavam por posições políticas próprias.

Com esta pesquisa, constatou-se que a expansão e reestruturação das universidades federais fazem-se necessárias para fazer frente às demandas educacionais e profissionais da sociedade e pela própria importância dessas instituições, que são responsáveis por $97 \%$ da produção científica nacional, representando 1,92\% da produção mundial. Nesse contexto, faz-se essencial a identificação das necessidades destas instituições, para que seja possível elaborar projetos que as atendam de forma eficiente e eficaz. Por isso, é necessária a participação de toda a comunidade acadêmica, tanto na identificação das necessidades quanto na elaboração de projetos, sob pena desses não atenderem aos anseios e passarem a sofrer oposição da comunidade que os deveria legitimar.

Assim, sugere-se a realização de estudos como este em outras universidades federais que passaram pelo processo de elaboração e implementação das propostas de adesão ao Reuni, com intuito de verificar se as mesmas estão atendendo às necessidades da comunidade acadêmica. Deve-se ressaltar, ainda, que o programa tem avançado significativamente na implementação de ações que, à medida que se concretizam, evidenciam a relevância do projeto para a universidade. (Artigo recebido em dezembro de 2010. Versão final em setembro de 2011).

\section{Referências bibliográficas}

Ahluwalia, R.; Burnkrant, R.e.; Unnava, H. R. Consumer response to negative publicity: the moderating role of commitment. Journal of Marketing Research, v. 37, n. 2, p. 203-214, maio 2000.

Araújo, M. A.; Pinheiro, H. D. Reforma gerencial do Estado e rebatimentos no sistema educacional: um exame do REUNI. Ensaio: Avaliação e Políticas Públicas em Educação, Rio de Janeiro, v. 18, n. 69, p. 647-668, out./dez. 2010.

Bardin, L. Análise de conteúdo. Lisboa: Edições 70, 1977.

Blackwell, Roger D.; Miniard, Paul W.; Engel, James F. São Paulo: Cengage Learning, 2008.

BrasiL. Decreto-lei no 6096, de 24 de abril de 2007. Institui o programa de apoio ao plano de reestruturação e expansão das universidades federais. Diário Oficial [da] República Federativa do Brasil, Brasília, DF, 24 abr.2007. Disponível em: <htpp://www.planalto.gov.br/ccivil_03/_Ato2007-2010/2007/Decreto/D6096.htm>. Acesso em: 18 nov. 2008. 
BRITO, E. P.; Heiden, R. Entre a reestruturação e a expansão das universidades federais brasileiras: movimentos que singularizam a travessia da Universidade Federal de Pelotas. Didáctica y Educación, n. 4, p.15-26, out./dez. 2011.

CAstro, R. P. Escola e mercado: a escola face à institucionalização do desemprego e da precariedade na sociedade colocada ao serviço da economia. Perspectiva, Florianópolis, v. 21, n. 1, p. 79-92, jan/jun. 2004.

Churchill, Gilbert A.; Peter, Paul. Criando valor para o cliente. São Paulo: Atlas, 2000.

Cobra, Marcos; Braga, R. Marketing educacional: ferramentas de gestão para instituições de ensino. São Paulo: Cobra Editora, 2004.

Cochran, W. G. Sampling techniques. 3ª ed. New York: John Wiley \& Sons, 1977.

Costa, D. M.; Barbosa, F. V.; Goto, M. M. O novo fenômeno da expansão da educação superior no Brasil. Reuni, Belo Horizonte, v.16, n. 1, p.15-29, jan.-abr., 2011.

DinIZ, L.C.O et al. Como os consumidores reagem ao recall de produtos? uma abordagem com equações estruturais considerando também indicadores formativos. In: Encontro Nacional Da Associação Nacional Da Pós-graduação Em Administração (ENANPAD), 28, 2004, Curitiba. Anais... Curitiba: ANPAD, 2004.

Dubois, B. Compreender o consumidor. Lisboa: Dom Quixote, 1993. Col. Gestão \& Inovação, v. 3.

GREY, C. Reinventing business schools: the contribution of critical management education. Academy of Management Learning and Education, v. 3, n. 2, p. 178-186, 2004.

Instituto Nacional de Estudos e Pesquisas Educacionais Anisio Teixeira (INEP). Sinopse estatística da educação superior, 2007. Disponível em: < http;/ / www.inep.gov.br/ superior/censosuperior/sinopse/>. Acesso em: 18 jul.2009.

Kotler, P.; Keller, K. L. Administração de marketing. 12a ed. Rio de Janeiro: Prentice Hall, 2006.

; Armstrong, G. Princípios de marketing. $7^{\text {a }}$ ed. Rio de Janeiro: Livros Técnicos e Científicos, 1999.

; Fox, K. F. Marketing estratégico para instituições educacionais. São Paulo: Atlas, 1994.

Las Casas, Alexandre Luzzi. Marketing: conceitos, exercícios, casos. $8^{\text {a }}$ ed. São Paulo: Atlas, 2009.

Lugão, R. G.; Abrantes, L. A.; Brunozi Júnior, A. C.; Silva, F. C.; Souza, A. P. Reforma universitária no Brasil: uma análise dos documentos oficiais e da produção científica sobre o Reuni - programa de apoio a planos de reestruturação e expansão das universidades federais. In: Colóquio Internacional Sobre Gestión Universitaria En América Del Sur, 10, 2010, Mar del Plata. Anais ... Blumenau, S.C., 2010.

Malhotra, N. Pesquisa de marketing: uma orientação aplicada. $3^{a}$ ed. Porto Alegre: Bookman, 2001.

Maslow, A. Motivation and personality. New York: Harper, 1954.

Mattar, F. N. Pesquisa de marketing. 3a ed. São Paulo: Atlas, 2001. 
Mazon, Gisele; Pereira Mauricio F.; Serra, Fernando A. R.; SoAres, Thiago C. Reuni e as fontes de financiamento das universidades federais brasileiras. In: Colóquio Internacional sobre Gestão Universitária na América do Sul, 9, 2009, Florianópolis. Anais ... Florianópolis, S.C., 2009.

MinistÉRIO DA EDUCAÇÃO. Reuni: reestruturação e expansão das universidades federais, diretrizes gerais. Brasília, 2007. Disponível em: < http://www1.universia.com.br/materia/ $\mathrm{img} /$ ilustra/2008/mar/artigos/diretrizesReuni.pdf>. Acesso em: 15 nov. 2008.

Ministério Da Educação. Diretrizes do Reuni. Brasília, 2007. Disponível em: <http:/ /www.comunicacao.ufscar.br/Reuni/apresentacaoReuni.pdf $>$. Acesso em: 10 nov. 2008.Parei Aqui.

Mowen, J. C.; Minor M. S. Comportamento do consumidor. São Paulo: Pearson Prentice Hall, 2003.

Programa Reuni de Orientação e Operacionalização da Pós-graduação Articulada À Graduação (PROPAG). Disponível em: <http://www.prograd.ufc.br/ index.php?option $=$ com_content\&view $=$ article\&id $=123 \&$ Itemid $=73>$. Acessado em: 15 de abril de 2010.

Ranking Web de Universidades Latino-Americanas. Top Latino América. Disponível em: http://www.webometrics.info/top100_continent_es.asp?cont=latin_america. Acesso em: 30 jul. 2010.

Ravazoli, M. L. R. A expansão na Universidade Federal do Paraná e na Universidade Tecnológica Federal do Paraná, antes e depois da implantação do Reuni (Programa de Apoio a Planos de Reestruturação e Expansão das Universidades Federais). 134 f. Dissertação de Mestrado. Universidade Federal do Paraná, Curitiba, 2011.

ReID, Michael. The Forgotten Continent: Political and Economic Progress in Latin America. Inter-American Dialogue. Disponível em: <http://www.thedialogue.org/ page.cfm?pageID=32\&pubID=1208>. Acesso em: 24 ago. 2011.

Richers, Raimer. O enigmático, mas indispensável consumidor: teoria e prática. Revista de Administração da USP, vol. 19, n. 3, jul./set., p. 46-56, 1984.

Rodrigues, M. O Reuni e suas controvérsias. Canal Vestibular. Disponível em: < http:// vestibular.brasilescola.com/especial/o-reuni-suas-controversias.htm >. Acesso em: 24 Ago. 2011.

ROWLEY, J. Beyond service quality dimensions in higher education and towards a service contract. Quality Assurance in Education, v. 5, n. 1, p. 7-14, 1997.

Schiffman, Leon G.; Kanuk, Leslie L. Comportamento do consumidor. $6^{a}$ ed. Rio de Janeiro: LTC, 2000.

Schmitt, Philipp; Skiera, Bernd; VAn Den Bulte, Christophe. Indicação por clientes pode dar tremendos resultados. Harvard Business Review. Brasil, agosto 2011.

Solomon, Michael. R. O comportamento do consumidor: comprando, possuindo e sendo. $5^{\text {a }}$ ed. Porto Alegre: Bookman, 2002.

Universidade Federal Do Ceará. Íntegra da proposta da UFC ao programa Reuni: projeto Reuni-UFC. Disponível em: <http:// www.prograd.ufc.br/index.php?option= com_content\&view=article\&id=119\&Itemid=61>. Acesso em: 10 nov. 2008. 
. Sintese da proposta da UFC ao programa Reuni. Disponível em: <http:// www.prograd.ufc.br/index.php?option $=$ com_content\&view =article\&id $=$ 119\&Itemid=61>. Acesso em: 10 nov. 2008.

Carta à Comunidade Acadêmica da UFC. Disponível em: <http:// www.ufc.br/portal/index.php?option=com_content\&task=view \&id= 7178\&Itemid=74>. Acesso em: 10 nov. 2008.

Urdan, André e Urdan, Flávio. Marketing Estratégico no Brasil. São Paulo: Atlas, 2010. 


\section{Resumo - Resumen - Abstract}

Reestruturação e expansão do ensino superior público: o programa Reuni na Universidade Federal do Ceará sob a visão dos alunos

Augusto Cézar de Aquino Cabral; Claudia Buhamra Abreu Romero; Emanuel Diego dos Santos Penha; Emanuel Dheison dos Santos Penha; Rafael de Almeida Alves e Tobias Coutinho Parente

Com a instituição do Programa de Apoio ao Plano de Reestruturação e Expansão das Universidades Federais (Reuni), o governo federal tenta criar condições para ampliar o acesso e a permanência dos estudantes na educação superior. Nesse contexto, esta pesquisa objetiva investigar a percepção dos estudantes dos dez centros acadêmicos da Universidade Federal do Ceará (UFC), regularmente matriculados no $2^{\circ}$ semestre de 2008 , em relação ao Reuni e à proposta de adesão da UFC ao mencionado programa, a partir de uma perspectiva mercadológica. Para a determinação da amostra de entrevistados foi utilizada a fórmula de Cochran, para populações finitas, e amostras aleatórias estratificadas, resultando em uma amostra de 378 estudantes para um nível de confiança de $95 \%$. Foram utilizadas variáveis que influenciam o comportamento do público-alvo, tais como renda, grupo social e idade, com foco no marketing educacional. Trata-se de uma pesquisa quantitativa quanto à sua natureza, descritiva quanto aos fins e realizada mediante survey. Constatou-se grande desconhecimento sobre o Reuni - 50,5\% dos entrevistados nunca ouviram falar sobre o programa. Percebeu-se ainda que os estudantes que possuem uma atitude negativa sobre o Reuni aprovam o conteúdo da proposta da UFC, da mesma maneira que os estudantes que não possuem essa atitude.

Palavras chave: Ensino Superior, Formação de Opinião, Reuni.

Reestructuración y ampliación de la educación superior pública: el programa Reuni en la Universidad Federal de Ceará bajo la visión de los alumnos

Augusto Cézar de Aquino Cabral; Claudia Buhamra Abreu Romero; Emanuel Diego dos Santos Penha; Emanuel Dheison dos Santos Penha; Rafael de Almeida Alves y Tobias Coutinho Parente

Con el establecimiento del Programa de Apoyo al Plan de Reestructuración y Expansión de Universidades Federales (Reuni), el Gobierno Federal de Brasil intenta crear condiciones para ampliar el acceso y la retención de estudiantes de educación superior. En este contexto, esta investigación tiene como objetivo investigar las percepciones de los estudiantes de la Universidad Federal de Ceará (UFC) en relación con Reuni y la composición propuesta del programa de UFC, desde una perspectiva de marketing. Se utiliza variables que influyen en el comportamiento del público objetivo, como los ingresos, edad y grupo social (KoTLER, 1999), centrándose en la comercialización de la educación (COBRA; BRAGA, 2004). Se trata de una investigación cuantitativa respecto a su naturaleza, descriptiva respecto a los fines, y realizada por medio de una encuesta. Había un desconocimiento generalizado sobre el Reuni: el 50,5\% de los encuestados nunca había oído hablar sobre el programa. También se observó que los estudiantes que tienen una actitud negativa acerca de la Reuni aprueban el contenido de la propuesta de la UFC, del mismo modo que los estudiantes que no tienen esa actitud.

Palabras clave: Educación Superior, Formación de la opinión, Reuni. 


\section{Restructure and expansion of public higher education: students' views on the Reuni program at the Federal University of Ceará \\ Augusto Cézar de Aquino Cabral; Claudia Buhamra Abreu Romero; Emanuel Diego dos Santos Penha; Emanuel Dheison dos Santos Penha; Rafael de Almeida Alves and Tobias Coutinho Parente}

With the establishment of the Program to Support the Plan of Restructuration and Expansion of Federal Universities (Reuni), the Brazilian Federal Government seeks to create conditions to increase access and retention of students in higher education. In this context, this paper investigates the perceptions of students from the Federal University of Ceará (UFC) about Reuni and the proposed membership of the UFC program. For this purpose, it was used the variables that affect the behavior of the public target that are income, age and social group (KOTLER, 1999), with focus on marketing education (COBRA; BRAGA, 2004). Based on Malhotra (2001), this research is classified as quantitative in nature, descriptive and conclusive as to the purposes, conducted through a survey. It was found a widespread ignorance about the Reuni: $50.5 \%$ of respondents had never heard about the program. It was noticed that students that have a negative attitude about Reuni approve the contents of the proposal from the UFC, in the same way that students who do not have that attitude.

Keywords: Higher Education, Opinion Formation e Reuni.

Augusto Cézar de Aquino Cabral

Doutor em Administração pela Universidade Federal de Minas Gerais (UFMG). Atualmente é Associado I da Universidade Federal do Ceará (UFC), atuando no Programa de Pós-graduação em Administração e Controladoria (PPAC). Contato: cabral@ufc.br

Claudia Buhamra Abreu Romero

Doutora em Administração de Empresas, com concentração em Marketing, pela Fundação Getúlio Vargas de São Paulo (FGV-SP). Atualmente é Professora Associada I da UFC. Contato: buhamra@ufc.br

Emanuel Diego dos Santos Penha

Graduando em Nutrição pela UFC (11 ${ }^{\circ}$ semestre). Atualmente é integrante do grupo de pesquisa de Nutrição Funcional. Contato: penhaemanuel@hotmail.com

Emanuel Dheison dos Santos Penha

Graduando em Administração de Empresa pela UFC (10 semestre). Atualmente é integrante do Núcleo de Estudos Organizacionais (NEO). Contato: emanueldheison@hotmail.com

Rafael de Almeida Alves

Graduando em Administração de Empresa pela UFC (10 semestre). Atualmente é integrante do Núcleo de Estudos Organizacionais (NEO).Contato: rafael_almeida_alves@yahoo.com.br

Tobias Coutinho Parente

Graduando em Administração de Empresa pela UFC (último semestre). Atualmente é monitor da disciplina Metodologia do Trabalho Científico. Contato: tobiascoutinho@gmail.com 